\title{
Effect of incremental dietary addition of 2-hydroxy-4-(methylthio) butanoic acid isopropyl ester on milk production and composition of dairy cows
}

\author{
R H Phipps ${ }^{1}$, A K Jones ${ }^{1}$, E Devillard ${ }^{2}$, P-A Geraert ${ }^{2}$, R Bennett ${ }^{2}$, C K Reynolds ${ }^{1}$ \\ ${ }^{1}$ University of Reading, Reading, United Kingdom, ${ }^{2}$ Adisseo France S.A.S., Commentry, France \\ Email: c.k.reynolds@reading.ac.uk
}

Introduction The incremental effects of 2-hydroxy-4-(methylthio) butanoic acid isopropyl ester (HMBi; MetaSmart ${ }^{\circledR}$ Dry, Adisseo, France), a methionine analogue, on production of lactating dairy cows have to our knowledge not been reported. Feeding HMBi to dairy cows receiving a maize silage based diet increased milk protein concentration, but not milk yield (Phipps et al., 2007). The failure to establish a significant milk yield response was attributed to relatively short treatment periods, which may have limited the expression of a milk yield response. In contrast, a significant milk yield response was observed in a continuous design lactation trial, but the response took 2 months to develop (St-Pierre and Sylvester, 2005). The objective of the present study was to determine the incremental effects of HMBi on feed intake and milk yield and composition of dairy cows over a 16-week treatment period.

Materials and methods Following a 1-week covariate period beginning in the 3rd week of lactation, sixty Holstein cows were allocated to one of four treatments ( 15 cows per treatment) in a randomized block design study. Treatments were based on an expected dry matter (DM) intake (DMI) of $24 \mathrm{~kg} / \mathrm{d}$ and were $0,25,50$, or $75 \mathrm{~g} \mathrm{HMBi} / \mathrm{d}$. Cows were assigned to treatments in blocks based on parity and covariate period milk yield and all animals received a total mixed ration (TMR) provided fresh on a daily basis that contained (\%) on a DM basis: grass silage (12.5), maize silage (37.5), and maize grain-based concentrates (50.0). Measured concentrations of crude protein, starch, and neutral detergent fibre for the TMRs fed averaged 171, 214, and $304 \mathrm{~g} / \mathrm{kg}$ DM, respectively. Milk yield was measured daily and milk composition was measured weekly. Data were analyzed as repeated measurements using mixed models procedures and a model testing fixed effects of treatment, week, parity, and their interactions and random effects of cow using preliminary measurements as a covariate. Orthogonal contrasts were used to partition the main effect of HMBi amount into linear, quadratic, and cubic effects.

Results Feeding increasing amounts of HMBi had a quadratic positive effect on DMI, with the greatest DMI at $50 \mathrm{~g} / \mathrm{d}$ of HMBi (Table 1). Milk yield was not affected by HMBi, although there was a numerical increase in energy corrected milk yield with HBMi supplementation (Table 1). Feeding HMBi increased milk protein concentration (Table 1), with the maximal response at $75 \mathrm{~g} / \mathrm{d}$. Feeding HMBi also linearly increased milk protein yield, whilst linearly decreasing milk urea concentration (Table 1). A linear increase was observed in both milk fat content and milk fat yield as HMBi intake increased (Table 1).

Table 1 Incremental effects of HMBi on DMI and milk production of lactating dairy cows.

\begin{tabular}{lllllllll}
\hline \hline & \multicolumn{4}{c}{ HMBi, g/d } & & \multicolumn{3}{c}{$\mathrm{P}<^{1}$} \\
\cline { 2 - 4 } \cline { 8 - 9 } & 0 & 25 & 50 & 75 & s.e. & Linear & Quad & Cubic \\
\hline DMI, kg/d & 22.6 & 23.4 & 24.2 & 22.8 & 0.42 & 0.413 & 0.010 & 0.236 \\
Milk yield, kg/d & 38.2 & 38.7 & 39.1 & 38.1 & 0.87 & 0.969 & 0.372 & 0.740 \\
Energy corrected milk, kg/d & 38.4 & 38.7 & 40.0 & 39.5 & 0.81 & 0.169 & 0.651 & 0.445 \\
Protein, \% & 3.00 & 2.99 & 3.01 & 3.17 & 0.041 & 0.005 & 0.037 & 0.563 \\
Fat, \% & 3.68 & 3.63 & 3.81 & 3.86 & 0.095 & 0.087 & 0.582 & 0.396 \\
Urea, mg/L & 267 & 256 & 248 & 224 & 5.9 & 0.001 & 0.259 & 0.431 \\
Protein, g/d & 1137 & 1156 & 1180 & 1189 & 23.9 & 0.078 & 0.821 & 0.837 \\
Fat, g/d & 1397 & 1394 & 1478 & 1463 & 38.0 & 0.091 & 0.862 & 0.274 \\
\hline \hline
\end{tabular}

${ }^{1}$ Probability for linear, quadratic (Quad) or cubic effects of HMBi.

Conclusions Feeding HMBi had positive effects on DMI, milk protein and fat concentrations, and milk protein and fat yields. Effects of HMBi on DMI may be due to effects of HMBi on rumen fermentation and thus rate of fibre degradation, or metabolic effects of improved amino acid balance. The increase in milk fat concentration has been observed previously (St-Pierre and Slyvester, 2005) and may reflect changes in rumen fermentation. The maximal effect on DMI was observed at $50 \mathrm{~g} / \mathrm{d}$. The lack of an effect of $75 \mathrm{~g} \mathrm{HMBi} / \mathrm{d}$ on DMI may be due to negative effects on rumen fermentation, or an imbalance of methionine and lysine supply. In this regard, the estimated ratio of metabolizable methionine to lysine was $0.26,0.31,0.36$, and 0.41 for the $0,25,50$, and $75 \mathrm{~g} / \mathrm{d} \mathrm{HMBi}$, respectively. There was a linear positive effect on milk protein and fat yields, which was reflected by a linear reduction in milk urea concentration that suggests an improvement in the utilization of absorbed amino acids. However, HMBi had no significant effect on milk yield, despite the increase in DMI observed. Results of the present study suggest that for the basal TMR fed, the optimal feeding rate of HMBi was between 25 and $75 \mathrm{~g} / \mathrm{d}$, but there was no indication of adverse effects when HMBi was fed at $75 \mathrm{~g} / \mathrm{d}$.

\section{References}

Phipps, R. H., C. K. Reynolds, D. I. Givens, A. K. Jones, P.-A. Geraert, E. Devillard, and R. Bennett. $2008 . \quad$ Effect of 2hydroxy-4-(methylthio) butanoic acid isopropyl ester on milk production and composition of lactating Holstein dairy cows. Journal of Dairy Science 91, 4002-4005.

St-Pierre, N. R., and J. T. Sylvester. 2005. Effects of 2-hydroxy-4-(methylthio) butanoic acid (HMB) and its isopropyl ester on milk production and composition by Holstein cows. Journal of Dairy Science, 2487-2497. 